\title{
Language Processing in Individuals with Non-fluent Aphasia: Evidence from Root and Synthetic Compound Nouns
}

\author{
Mousa Ghonchepour (iD ${ }^{1,}{ }^{*}$ and Omid Azad ${ }^{2}$ \\ ${ }^{1}$ Language and Literature Department, Farhangian University, Tehran, Iran \\ ${ }^{2}$ University of Gonabad, Gonabad, Iran \\ "Corresponding author: Language and Literature Department, Farhangian University, Tehran, Iran. Email: m_ghonchepour@yahoo.com
}

Received 2020 November 28; Revised 2021 June 29; Accepted 2021 July 07.

\begin{abstract}
Background: Neurolinguists are increasingly inclined to study the language behavior of patients with aphasia (PWAs) to discover more about the relationship between the brain and language.

Objectives: This study investigated the production of synthetic and root compound nouns in the PWAs to discover how these lexemes were processed.

Methods: Using a confrontation naming task, four PWAs (two patients with Broca aphasia and two patients with transcortical motor aphasia) named 80 random black and white drawings of simple and compound nouns. They also repeated the nouns through an auditory repetition task. Compound nouns were of two root and synthetic types. Root nouns belonged to the noun-noun, and synthetic compounds belonged to the noun-verb category.

Results: There was a significant difference between the affected components in naming and repetition of compound nouns. Moreover, there was a significant difference between naming and repetition of simple and compound nouns. There was no significant difference between naming and repetition of root and synthetic nouns.

Conclusions: PWAs process compound nouns through the dual-route model. They cannot retrieve the phonological forms of compound nouns, but they retain their knowledge of word-formation, indicating the modularity of linguistic ability. Morphological structure plays a role in word processing.
\end{abstract}

Keywords: Word Processing, Language, Humans, Brain, Aphasia

\section{Background}

In recent years, there seems to be an increasing preference to study the language behavior of patients with aphasia (PWAs) to discover the language-mind relationship. Having lost their particular linguistic ability, PWAs make errors such as paraphasia, omission, neologism, circumlocution, simple for compound, and left-right inversion in producing compound words. The processing models provide empirical evidence for neurolinguists to discover how compound words are stored and retrieved. Among them, the full-listing (1) predicts that all complex words are stored independently in the lexicon. Moreover, they are represented and retrieved in full forms, such as simple words. The full-parsing model predicts that all complex words are processed through morphological decomposition. The units stored in the mental dictionary are morphemes, and compound words are parsed into their morphemes (2-5). The dual-route model implies that specific constructions are stored and accessed in full forms, and some others are decomposed into their morphemes.
Moreover, irregularly derived forms are processed in a fulllisting route, while regularly inflected forms are processed in a full-parsing route. Moreover, these two routes are independent and competitive (6-10).

"A compound noun is a word composed of two or more simple words, free or bounded morphemes, or free grammatical morphemes" (11). Root and synthetic types of compounds have been referred to in the latest studies in Persian (11, 12), English (13), and Dutch (14). The syntactic head (to distinguish the grammatical category) of a root compound is non-verbal (e.g., gâvsanduq, safe, literally: "strongbox"; box is the head). The syntactic head of a synthetic compound is a verb-derived element, and the nonverbal constituent is an argument (e.g., simčin, clipper, literally: "wire cut"; wire is the argument, and cut is the head).

\section{Objectives}

Since psycholinguistic studies have always focused on inflection and derivation processing (15-18), and com- 
pound processing is still a topic of debate, this article aims at investigating the mentioned models to discover the one (s) Persian PWAs use to process compound words. Moreover, studies on languages such as Persian, which are highly productive in word-formation (19) and have not been noticed so far, are useful to examine error patterns to decide whether the structures of poly-morphemic words play a role in their representation.

\section{Methods}

\subsection{Participants}

\subsubsection{Non-impaired Subjects}

The non-impaired individuals were four (one female and three males) monolingual participants matched with PWAs based on the number, gender, age, educational level, native language, and handedness. They all were righthanded with no history of neurological or psychiatric disorders. The PWAs were of the ischemic stroke type (see Appendix 1 for more information).

\subsubsection{Impaired Subjects}

A purposive sampling technique was used to recruit PAWs for this multiple case study. They were selected from the PWAs attending speech therapy clinics of Shafa Hospital and Welfare and Rehabilitation Centers in Kerman, Iran. They suffered from a cerebrovascular accident (CVA), causing left hemisphere damage. Neurologists and speech therapists made the initial diagnosis of aphasia, and the aphasia type was determined through the diagnostic aphasia test (20). It was used to assess six primary skills, including naming, oral comprehension, repetition, oral reading, reading comprehension, and writing. The linguistic profiles of PWAs are presented in Table 1.

The Mann-Whitney U-test showed that there was a difference in naming, repetition, and writing skills, while there was no difference between these two groups regarding the oral comprehension, oral production, and reading comprehension variables.

This multiple case study was conducted following the ethical guidelines in human research and was confirmed with the Research Ethics Committee of Farhangian University (permission number: 2020/52200/2720/100). The consent was obtained before doing the tests. A description of the subjects' characteristics is given below:

- Participant 1: M.L. was a 69-year-old man with Broca aphasia. He had a stroke in February 2007. His magnetic resonance imaging (MRI) showed brain damage in his left hemisphere temporal lobe and a lesser involvement of the left frontal lobe. Right side hemiplegia was observed during the investigation. He overused body language while producing effortful and non-fluent speech. He committed more errors in naming compared to repetition. Contrary to production disorders, his comprehension ability was preserved.

- Participant 2: K.A. was a 55-year-old man with Broca aphasia. He had a stroke in November 2005 and was admitted to the hospital with a sudden onset of right-side weakness. His MRI revealed swelling involving the left insula, temporal lobe, and inferior frontal lobe. During the test, he displayed hemiplegia symptoms on his body's right side, notably the upper part. His spontaneous speech was nonfluent, with fewer pauses compared to naming. His comprehension was good, although he had difficulty doing complex orders.

- Participant 3: R.E. was a 54-year-old woman with transcortical motor aphasia. She had a stroke in August 2005 that caused paralysis of her right side. Her MRI showed that the lesion involved the upper left parietal area. At the time of the test, we found no severe symptoms of hemiplegia. Her spoken language was non-fluent, accompanied by excessive use of paraphasias and perseverations. She had difficulty producing the opening phonemes of compound nouns while naming.

- Participant 4: T.P. was a 56-year-old man with transcortical motor aphasia. He had a stroke in March 2007 at the age of 54 . His MRI revealed damage involving frontal, temporal, and parietal lobes. The damage also extended to the internal capsule and subcortical white matter of the left hemisphere. During the test, hemiplegia signs were seen in his right upper part. Contrary to pauses in his slow telegraphic spontaneous speech, his repetition and comprehension were good.

\subsection{Stimuli}

The stimuli included 40 simple and 40 compound nouns (20 root and 20 synthetic nouns). The root nouns belonged to the noun-noun category, and the synthetic compounds belonged to the category of the noun-verb stem. The root and synthetic compound nouns were selected from the Ph.D. dissertations of Xabbaz (11) and Ghonchepour (12), respectively. The simple nouns were extracted from the Persian corpus entitled Peykare (21), involving 110 million spoken and written words. In selecting nouns, the most pictorial and frequent ones [43.18\% root (11) and 98.3\% synthetic (12)] were used.

As Persian is a syllable-timed language, the word length does not significantly contribute to the naming of pictures (22). However, we used simple nouns with two or more syllables to balance them against compounds. Three linguists independently assessed compound types and the error classifications in a rating task without any disagreement. Appendices 2, 3, and 4 present data on root and synthetic compound nouns as well as simple nouns, respectively. 


\begin{tabular}{|c|c|c|c|c|c|c|c|c|}
\hline \multirow{3}{*}{$\begin{array}{l}\text { Language } \\
\text { Skills }\end{array}$} & \multicolumn{8}{|c|}{ PWAs } \\
\hline & \multicolumn{3}{|c|}{$\operatorname{Broca}(\mathrm{N}=2)$} & \multicolumn{3}{|c|}{ Transcortical Motor $(\mathrm{N}=2)$} & \multicolumn{2}{|c|}{ Between Groups } \\
\hline & M.L. & K.A. & Mean \pm SD & R.E. & T.P. & Mean \pm SD & $\mathbf{U}$ & $\mathbf{P}^{\mathbf{a}}$ \\
\hline Naming & 24 & 26.25 & $25.12 \pm 1.52$ & 40.45 & 42.25 & $41.35 \pm 1.27$ & 4 & 0.009 \\
\hline $\begin{array}{l}\text { Oral compre- } \\
\text { hension }\end{array}$ & 55.50 & 58.28 & $56.89 \pm 1.96$ & 58.33 & 60.66 & $59.45 \pm 1.64$ & 17 & 0.338 \\
\hline Repetition & 24.75 & 26.75 & $25.75 \pm 1.41$ & 59.75 & 62.75 & $61.25 \pm 2.12$ & 0 & 0.002 \\
\hline Oral reading & 24.66 & 25.33 & $24.99 \pm 0.47$ & 28.66 & 28.33 & $28.49 \pm 0.23$ & 0 & 0.121 \\
\hline $\begin{array}{l}\text { Reading com- } \\
\text { prehension }\end{array}$ & 47.25 & 48.66 & $47.95 \pm 0.99$ & 59.25 & 60.66 & $59.95 \pm 0.99$ & 7 & 0.242 \\
\hline Writing & 35.25 & 34.75 & $35 \pm 0.35$ & 48.65 & 46.34 & $47.49 \pm 1.63$ & 4.5 & 0.001 \\
\hline
\end{tabular}

${ }^{\text {a }}$ The Mann-Whitney U-test.

Before the experiment, we controlled word frequency for nouns and also name agreement, familiarity, age acquisition, and visual complexity predictors for 80 linedrawing pictures of a naming task. Twenty non-impaired subjects rated the variables for each picture on a 5-point scale within 5 seconds. The comparison of the predictors for simple, root, and synthetic nouns is shown in Table 2.

There was no significant difference in visual complexity $(\mathrm{F}=1.99, \mathrm{P}=0.142)$, familiarity $(\mathrm{F}=2.181, \mathrm{P}=0.120)$, name agreement $(\mathrm{F}=1.529, \mathrm{P}=0.223)$, acquisition age $(\mathrm{F}=1.107$, $\mathrm{P}=0.336)$, and frequency $(\mathrm{F}=0.185, \mathrm{P}=0.831)$ among the names of root, synthetic, and simple nouns.

\subsection{Instruments}

Picture naming and repetition tasks were used in this multiple case study. In picture naming, 40 pictures of compound nouns were intermixed with 40 pictures of simple nouns. The PWAs named the pictures while confronting them. The stimuli of the repetition task were the lexical stimuli used in the confrontation naming. They were the names of simple and compound nouns. The participants listened to a word and immediately repeated it.

\subsection{Procedure}

Picture naming and repetition tasks were separately managed for each PWA. Each picture whose size filled a space of $450 \times 600$ pixels was displayed on the screen separately. In the naming task, PWAs named the pictures as succinctly as possible. In the repetition task, the participants repeated words immediately after the examiner repeated them. If the participants' pause time exceeded 5 seconds, they were asked to repeat the next noun. During the presentation, the stimuli were counterbalanced by random distribution from one participant to another. Naming and repetition tasks lasted 20 and 15 minutes, respectively. The naming task preceded the repetition to avoid participants' pre-exposing to the names of pictures. The subjects' production was recorded, and then their errors were classified and analyzed. Their error classifications included semantic verbal paraphasia (the real word being of the same semantic field); omission (no answer); circumlocution (replacing a word by its function); neologism (a nonexistent compound word); formal paraphasia (the produced word phonemically related to the target); verbal formal paraphasia (the real word formally similar to the target); simple for compound (producing one component of a compound), and left-right inversion (constituents of compounds used instead of each other).

\subsection{Data Analysis}

The SPSS software version 20 was employed for descriptive and inferential statistics. The Mann-Whitney U-test was used to compare the accuracy of the simple and compound nouns' naming with their repetition between nonimpaired subjects and PWAs. The Kruskal-Wallis H-test was employed to compare the mean ranks of the affected components of compound nouns. A P-value of less than or equal to 0.05 was considered significant.

\section{Results}

\subsection{Performance Comparisons of PWAs and Non-impaired Par- ticipants}

Non-impaired subjects named simple and compound nouns 100 and 99\% accurately. They repeated them 100\% correctly. PWAs were $91.87 \%$ accurate in simple naming and $18.75 \%$ in compound naming. Their accuracy for simple and compound repetitions was 100 and 50\%, respectively. The mean ranks of non-impaired individuals and PWAs in naming were 12.50 and 4.50 , and their mean ranks for repetition were 10.50 and 6.50, respectively. The Mann-Whitney U-test showed that the mean ranks of these two groups were significantly different in naming $(\mathrm{U}=0, \mathrm{P}=0.001)$ and repetition $(\mathrm{U}=16, \mathrm{P}=0.027)$. 


\begin{tabular}{|c|c|c|c|c|c|}
\hline \multirow{3}{*}{ Variables } & \multicolumn{3}{|c|}{ Nouns } & \multicolumn{2}{|c|}{ Between Groups } \\
\hline & \multirow{2}{*}{ Simple $(N=40)$} & \multicolumn{2}{|c|}{$\operatorname{Compound}(\mathrm{N}=40)$} & \multirow{2}{*}{$\mathbf{F}$} & \multirow{2}{*}{ P-Value $^{\text {b }}$} \\
\hline & & $\operatorname{Root}(N=20)$ & Synthetic $(\mathbf{N}=\mathbf{2 0})$ & & \\
\hline Word frequency & $4.72 \pm 0.07$ & $4.60 \pm 0.502$ & $4.45 \pm 0.502$ & 0.185 & 0.831 \\
\hline Name agreement & $4.15 \pm 1.07$ & $3.75 \pm 1.33$ & $4.20 \pm 0.61$ & 1.529 & 0.223 \\
\hline Familiarity & $4.42 \pm 0.90$ & $4.10 \pm 0.78$ & $3.65 \pm 1.18$ & 2.181 & 0.120 \\
\hline Age acquisition & $4.30 \pm 0.64$ & $3.95 \pm 0.94$ & $4.20 \pm 0.69$ & 1.107 & 0.336 \\
\hline Visual complexity & $4.45 \pm 0.67$ & $4.30 \pm 0.73$ & $4.45 \pm 0.68$ & 1.99 & 0.142 \\
\hline
\end{tabular}

${ }^{\text {a }}$ Values are expressed as Mean $\pm \mathrm{SD}$.

b The ANOVA test.

Table 3 reports the type, the percentage, and the number of errors of PWAs in naming and repetition tasks (for compound and simple nouns). There was a significant departure from normality in PWAs' naming $[\mathrm{w}(8)=0.896, \mathrm{P}$ $=0.26]$ and repetition $[\mathrm{w}(8)=0.743, \mathrm{P}=0.007]$.

\subsection{Comparisons of the Affected Individual Constituents and} the Whole Compounds in PWAs

Table 4 shows a significant difference between the naming of simple and compound nouns $(\mathrm{U}=4, \mathrm{P}=0.003)$ and their repetition $(\mathrm{U}=12, \mathrm{P}=0.011)$. Moreover, Table 5 shows a difference between the individual constituents (first or second) and the whole compounds affected by errors in the naming $[\mathrm{H}(2)=8.171, \mathrm{P}=0.017]$ and repetition $[\mathrm{H}$ $(2)=3.322, \mathrm{P}=0.046]$ tasks of compound nouns.

\subsection{Error Comparisons of the Noun-Verb Stem and Noun-Noun Compounds in PWAs}

The PWAs' errors in naming noun-noun and noun-verb stems were 83.75 and $78.75 \%$, and their repetition errors in root and synthetic nouns were 52.5 and $47.5 \%$, respectively. Table 6 shows no significant difference between the naming of the noun-verb stem and the noun-noun categories $(\mathrm{U}=6.5, \mathrm{P}=0.642)$ and their repetition $(\mathrm{U}=7.5, \mathrm{P}=0.885)$, while the naming of root and synthetic compounds were different from their repetition $(U=10.5, P=0.022)$.

\section{Discussion}

In this study, we examined whether compound nouns were processed through their individual constituents or the whole compounds. Previous studies (1-10) addressing this issue did not reach a definitive agreement on lexeme processing models, being a stimulus to investigate how individuals with non-fluent aphasia process compound nouns.

The frequency of naming errors was the same in the noun-verb and the noun-noun categories, as well as the frequency of repetition errors. These facts indicated that the category type did not affect the processing of compound nouns. The results also showed that the frequency of nounnoun category errors, both in naming and repetition, was more than the noun-verb stem category, proving easier processing of nouns with the noun-verb stem than nounnoun category. More errors in naming simple and compound nouns compared to their repetition proved easier processing of repetition.

The PWAs replaced the whole compound with a new lexeme (as irrelevant semantic verbal paraphasia) such as nâme, letter, in place of râhâhan, railroad, literally: "road iron" or nâxongir, nail scissor, literally: "nail cut", in place of kamân?arre, hacksaw, literally: "bow saw." They also committed neologism errors such as tiyani and šikšel, in place of širjuš, boiling milk, literally: "milk boiling" and simboksel, wire rope, literally: "wire tow." These errors affecting both parts ofthe root and synthetic compounds suggest holistic processing of compounds. On the other hand, they produced substitution errors such as dâru, drug, in place of dâruxâne, drugstore, literally: "drug-house"; čang, claw, in place of xarčang, crab, literally: "wrinkle-claw"; nâxon, nail, in place of nâxongir, nail scissor, literally: "nail cut", and formal paraphasias such as "damâčand", in place of damâsand, thermometer, literally: "temperature measuring" and "xaškeš”, in place of xatkeš, ruler, literally: "line drawing." The phoneme omission or change in one component of the compounds implies their decomposition processing. The fact that different types of errors occur in individual constituents or the whole compounds indicates that the dual-routes (full-listing and fullparsing) are used in naming and repetition processing, but full-listing and full-parsing are the dominant routes, respectively, in naming and repetition. These discoveries uphold past research disclosures (6-10), exhibiting that compound words were processed as unitary lexical units or as individual constituents, were dissected through a combinatorial mechanism.

Naming and repetition errors of simple nouns with a simpler structure were less than that of compound nouns. 


\begin{tabular}{|c|c|c|c|c|c|c|}
\hline \multirow{2}{*}{ Error Types } & \multicolumn{2}{|c|}{ Simple Nouns } & \multirow{2}{*}{ Total } & \multicolumn{2}{|c|}{ Compound Nouns } & \multirow{2}{*}{ Total } \\
\hline & Naming & Repetition & & Naming & Repetition & \\
\hline Semantic verbal paraphasia & $1(0.3125)$ & $0(0)$ & $1(0.3125)$ & $27(8.4375)$ & $4(1.25)$ & $31(9.6875)$ \\
\hline Omission & $4(1.25)$ & $0(0)$ & $4(1.25)$ & $45(14.0625)$ & $0(0)$ & $45(14.0625)$ \\
\hline Circumlocution & $0(0)$ & $0(0)$ & $0(0)$ & $17(5.3125)$ & $0(0)$ & $17(5.3125)$ \\
\hline Neologism & $0(0)$ & $0(0)$ & $0(0)$ & $7(2.1875)$ & $13(4.0625)$ & $20(6.25)$ \\
\hline Formal paraphasia & $3(0.9375)$ & $0(0)$ & $3(0.9375)$ & $14(4.375)$ & $43(13.4375)$ & $57(17.8125)$ \\
\hline Verbal formal paraphasia & $0(0)$ & $0(0)$ & $0(0)$ & $3(0.9375)$ & $0(0)$ & $3(0.9375)$ \\
\hline Simple for compound & $0(0)$ & $0(0)$ & $0(0)$ & $16(5)$ & $17(5.3125)$ & $33(10.3125)$ \\
\hline Left-right inversion & $0(0)$ & $0(0)$ & $0(0)$ & $1(0.3125)$ & $3(0.9375)$ & $4(1.25)$ \\
\hline Total & $8(2.5)$ & $0(0)$ & $8(2.5)$ & $130(40.625)$ & $80(25)$ & $210(65.625)$ \\
\hline
\end{tabular}

${ }^{a}$ Values are expressed as No. (\%).

\begin{tabular}{|c|c|c|c|c|c|c|c|}
\hline \multirow[b]{2}{*}{ Performances } & \multicolumn{4}{|c|}{ Noun Groups $(\mathbf{N}=\mathbf{8 0})$} & \multicolumn{3}{|c|}{ Test Statistics (Between Groups) } \\
\hline & $\begin{array}{l}\text { Descriptive Statistics } \\
\quad(\text { Mean } \pm \text { SD })\end{array}$ & \multicolumn{2}{|c|}{ Simple (Mean Rank) } & Compounds (Mean Rank) & $\mathbf{U}$ & \multicolumn{2}{|c|}{$\mathbf{P}^{\mathbf{a}}$} \\
\hline Naming & $8.62 \pm 12.62$ & \multicolumn{2}{|c|}{5} & 12 & 4 & \multicolumn{2}{|c|}{0.003} \\
\hline Repetition & $5 \pm 11.34$ & \multicolumn{2}{|c|}{6} & 11 & 12 & \multicolumn{2}{|c|}{0.011} \\
\hline \multicolumn{8}{|c|}{ a The Mann-Whitney U-test. } \\
\hline & \multicolumn{4}{|c|}{ Affected constituents $(N=130)$} & \multicolumn{3}{|c|}{ Test Statistics (Between Groups) } \\
\hline Performances & $\begin{array}{l}\text { Descriptive Statistics } \\
\quad(\text { Mean } \pm S D)\end{array}$ & $\begin{array}{c}\text { First (Mean } \\
\text { Rank), }(\mathbf{N}=\mathbf{4 0})\end{array}$ & $\begin{array}{l}\text { Second (Mean } \\
\text { Rank), }(\mathrm{N}=\mathbf{2 5})\end{array}$ & $\begin{array}{l}\text { First \& Second (Mean } \\
\text { Rank), (N=65) }\end{array}$ & $\mathbf{H}$ & df & $\mathbf{P}^{\mathbf{a}}$ \\
\hline Naming & $2.90 \pm 1.44$ & 3.38 & 4.75 & 8.60 & 8.17 & 2 & 0.017 \\
\hline Repetition & $3 \pm 1.47$ & 9 & 5 & 3.5 & 3.32 & 2 & 0.046 \\
\hline
\end{tabular}

${ }^{\mathrm{a}}$ The Kruskal Wallis H-test.

\begin{tabular}{|c|c|c|c|c|c|}
\hline \multirow[b]{2}{*}{ Performances } & \multicolumn{3}{|c|}{ Noun Groups } & \multicolumn{2}{|c|}{ Test Statistics (Between Groups) } \\
\hline & $\begin{array}{l}\text { Descriptive Statistics } \\
\quad(\text { Mean } \pm \text { SD })\end{array}$ & $\begin{array}{l}\text { Noun-Noun (Mean Rank), } \\
\qquad(\mathbf{N}=\mathbf{2 0})\end{array}$ & $\begin{array}{c}\text { Noun-Verb (Mean Rank), (N } \\
=20)\end{array}$ & $\mathbf{U}$ & $\mathbf{P}^{\mathbf{a}}$ \\
\hline Naming & $16.25 \pm 3.73$ & 5 & 4 & 6.50 & 0.642 \\
\hline Repetition & $10 \pm 5.75$ & 4.63 & 4.38 & 7.50 & 0.885 \\
\hline
\end{tabular}

${ }^{a}$ The Mann-Whitney U-test.

This finding is in line with the results of previous studies (1-5), revealing the role of morphological structure in processing words.

Left-right inversion errors such as mor $\gamma$ toxm in place of toxmmor $\gamma$, egg, literally: "egg hen", ?âhanrâh in place of râhâhan, railroad, literally: "road iron", and also the production of neologisms such as mahrir in place of mâšintahrir, typewriter, literally: "machine writing" and madâš in place of madâdtarâš, sharpener, literally: "pencil sharpen" in repetition showed that the PWAs changed both components of the compound nouns (the whole composition) and produced a new item, a merger of the two constituents. These errors suggested that the PWAs could realize the underlying constituents composing the compound nouns but were unable to produce the right phonological form. 
In formal paraphasia errors such as bâru in place of pâru, snow shovel, literally: "foot sweep" or âkpâš in place of âbpâš, watering pot, literally: "water spray," the PWAs preserved morphological structures contrary to the affected phonological forms, indicating that they maintained the word-formation knowledge of compound nouns, but were unable to employ them. In other words, they could not retrieve the phonological knowledge correctly, and thus, the wrong substituted phonemes occurred. These findings confirm the modular competence of language. That is, one aspect of linguistic ability may remain intact while another shows the deficit.

\subsection{Conclusions}

This study showed that the PWAs had more difficulty naming the compound words than repeating them, proving the dissociation between naming and repetition. Moreover, the category type of the constituents of compounds did not play a role in processing root and synthetic compounds. Occurring errors in whole words and their constituents simultaneously indicated the dualroute processing. Fewer errors in simple nouns than the compounds explained the contribution of morphological structure to the production. The implication of these discoveries is useful for clinical experts to represent efficient remedial services to improve the PWAs' output. Using repetition tasks and simple words will enhance PWAs' linguistic ability. Moreover, understanding the linguistic behavior of PWAs makes it possible to draw a more precise profile of their anomalies theoretically. The small number of PWAs (sampling bias) and the researcher bias were limitations that made the findings of this study ungeneralizable. The findings of this study will be useful as long as they are in line with the results of other studies, so it is recommended to do another study on processing compound nouns in PWAs to make these findings conclusive.

\section{Supplementary Material}

Supplementary material(s) is available here [To read supplementary materials, please refer to the journal website and open PDF/HTML].

\section{Acknowledgments}

We would like to thank the PWAs who participated eagerly in this study.

\section{Footnotes}

Authors' Contribution: Developing the original idea, preparing and writing the manuscript, collecting the clinical data, preparing the abstract, analysis, and data revision, and a guarantor, M.G.; Critical revision of the manuscript for important intellectual content, statistical analysis, and interpretation of the clinical data, O.A. All authors read and approved the final manuscript.

Conflict of Interests: The authors have no conflict of interest.

Ethical Approval: This multiple case study was conducted following the ethical guidelines in human research and was confirmed with the Research Ethics Committee of Farhangian University (permission number: 2020/52200/2720/100).

Funding/Support: This study did not receive any financial support.

Informed Consent: The consent was obtained before doing the tests.

\section{References}

1. Butterworth B. Lexical representation. Development, writing and other language processes (language production). 2. London, UK: Academic Press Inc; 1983.

2. Andrews S, Miller B, Rayner K. Eye movements and morphological segmentation of compound words: There is a mouse in mousetrap. Eur Cognit Psychol. 2004;16(1-2):285-311. doi: 10.1080/09541440340000123.

3. Pollatsek A, Hyönä J. The role of semantic transparency in the processing of Finnish compound words. Lang Cogn Neurosci. 2007;20(1-2):26190. doi: 10.1080/01690960444000098.

4. Taft M. Morphological decomposition and the reverse base frequency effect. Q J Exp Psychol A. 2004;57(4):745-65. doi: 10.1080/02724980343000477. [PubMed: 15204131].

5. Libben G, Jarema G. Conceptions and questions concerning morphological processing. Brain Lang. 2004;90(1-3):2-8. doi: 10.1016/j.bandl.2003.12.005. [PubMed: 15172519].

6. Kuperman V, Schreuder R, Bertram R, Baayen RH. Reading polymorphemic Dutch compounds: Toward a multiple route model of lexical processing. J Exp Psychol Hum Percept Perform. 2009;35(3):876-95. doi: 10.1037/a0013484. [PubMed:19485697].

7. Marelli M, Luzzatti C. Frequency effects in the processing of Italian nominal compounds: Modulation of headedness and semantic transparency.J Mem Lang. 2012;66(4):644-64. doi:10.1016/j.jml.2012.01.003.

8. Xu J, Taft M. The effects of semantic transparency and base frequency on the recognition of English complex words. J Exp Psychol Learn Mem Cogn. 2015;41(3):904-10. doi: 10.1037/xlm0000052. [PubMed: 25151246].

9. Koester D, Gunter TC, Wagner S. The morphosyntactic decomposition and semantic composition of German compound words investigated by ERPs. Brain Lang. 2007;102(1):64-79. doi 10.1016/j.bandl.2006.09.003. [PubMed: 17055044].

10. Koester D, Holle H, Gunter TC. Electrophysiological evidence for incremental lexical-semantic integration in auditory compound comprehension. Neuropsychologia. 2009;47(8-9):1854-64. doi: 10.1016/j.neuropsychologia.2009.02.027. [PubMed: 19428417].

11. Xabbaz M. [Root compounds [dissertation]]. Tehran, Iran: University of Allame Tabataba'i; 2007. Persian.

12. Ghonchepour M. [Verbal compounding [dissertation]]. Tehran, Iran: University of Allame Tabataba'i; 2014. Persian.

13. Harley H. Compounding in distributed morphology. In: Lieber R Stekauer P, editors. The Oxford handbook of compounding. Oxford, England: Oxford University Press; 2009. p. 105-29.

14. Don J. IE, germanic: Dutch. In: Lieber R, Stekauer P, editors. The Oxford handbook of compounding. Oxford, England: Oxford University Press; 2009. p. 370-87. 
15. Longtin CM, Meunier F. Morphological decomposition in early visual word processing. J Mem Lang. 2005;53(1):26-41. doi: 10.1016/j.jml.2005.02.008.

16. Luck M, Hahne A, Clahsen H. Brain potentials to morphologically complex words during listening. Brain Res. 2006;1077(1):144-52. doi: 10.1016/j.brainres.2006.01.030. [PubMed: 16487499].

17. Thompson CK, Mack JE. Grammatical Impairments in PPA. Apha siology. 2014;28(8-9):1018-37. doi: 10.1080/02687038.2014.912744. [PubMed: 25642014]. [PubMed Central: PMC4306464].

18. Kuperman V, Bertram R, Baayen RH. Morphological dynamics in compound processing. Lang Cogn Process. 2008;23(7-8):1089-132. doi: 10.1080/01690960802193688.
19. Ghonchepour M. [Synthetic compounding: A morphological or syntactic process? A corpus-based study].Zaban Pazhuhi.2018;10(28):14973. Persian. doi: 10.22051/jlr.2017.10483.1146.

20. Nilipour R. [Diagnostic aphasia test]. Tehran, Iran: Iran University of Medical Sciences Press; 1994. Persian.

21. Bijankhan M, Sheykhzadegan J, Bahrani M, Ghayoomi M. Lessons from building a Persian written corpus: Peykare. Lang Resour Eval. 2010;45(2):143-64. doi: 10.1007/s10579-010-9132-x.

22. Bakhtiar M, Nilipour R, Weekes BS. Predictors of timed picture naming in Persian. Behav Res Methods. 2013;45(3):834-41. doi: 10.3758/s13428-012-0298-6. [PubMed: 23292568]. 